\title{
Two mechanisms of cardiac stem cell-mediated cardiomyogenesis in the adult mammalian heart include formation of colonies and cell-in-cell structures
}

\author{
Galina B. Belostotskaya ${ }^{1,2}$, Irina V. Nerubatskaya ${ }^{1,2}$ and Michael M. Galagudza ${ }^{3}$ \\ ${ }^{1}$ Sechenov Institute of Evolutionary Physiology and Biochemistry of Russian Academy of Sciences, Russian Federation, Saint- \\ Petersburg, Russian Federation \\ ${ }^{2}$ Almazov National Medical Research Centre, Russian Federation, Saint-Petersburg, Russian Federation \\ ${ }^{3}$ ITMO University, Russian Federation, Saint-Petersburg, Russian Federation \\ Correspondence to: Galina B. Belostotskaya, email: gbelost@mail.ru \\ Keywords: cardiac stem cells (CSCS); CSC-derived colony; cell-in-cell structures (CICSs); transitory amplifying cells (TACs); \\ cardiomyogenesis \\ Abbreviations: CICSs, cell-in-cell structures; CMs, cardiomyocytes; CSCs, cardiac stem cells; TACs, transitory amplifying cells \\ Received: November 14, $2017 \quad$ Accepted: August 16, $2018 \quad$ Published: September 25, 2018 \\ Copyright: Belostotskaya et al. This is an open-access article distributed under the terms of the Creative Commons Attribution \\ License 3.0 (CC BY 3.0), which permits unrestricted use, distribution, and reproduction in any medium, provided the original author \\ and source are credited.
}

\section{ABSTRACT}

Aims: Because the mechanism of mature cardiomyocyte (CM) development from cardiac stem cells (CSCs) is not fully understood, we explored the involvement of CSCs into two pathways of cardiomyogenesis in adult mammalian heart: (1) via colony formation and (2) by means of intracellular development of CSCs inside CMs followed by the formation of "cell-in-cell structures" (CICSs).

Methods and Results: Using immunostaining and confocal microscopy, we studied the presence of CSC-derived colonies, CICSs and transitory amplifying cells (TACs), released from ruptured CICSs, in a suspension of ex vivo freshly isolated myocardial cells of mammals of different age and species, human including. All subsets of CSCs (c-kit ${ }^{+}, \mathrm{Sca}^{+} \mathbf{1}^{+}$and $\mathrm{Isl-1}{ }^{+}$) were found in mammals of different age. It was shown that c-kit ${ }^{+}$and Sca-1 ${ }^{+}$CSCs produce both colonies and CICSs. However, Isl-1 ${ }^{+}$CSCs seem to be involved in cardiac growth during first month of age only both through colony formation and CICS generation. In turn, the studies on myocardial cell suspensions of adult C57/bl6N mice, one-year-old bull and 45-year-old woman not only confirmed the involvement of c-kit ${ }^{+}$and Sca-1 ${ }^{+}$CSCs in both mechanisms of cardiomyogenesis, but also showed that Isl-1+ colonies are present in the myocardium of adult mice and rarely in human.

Conclusions: The presence of CSC-derived colonies, CICSs and TACs in all experimental specimens of myocardium proved our previous hypothesis about two pathways that generate new CMs in adult heart. Moreover, we suggest that TACs play a central role in self-renewal of myocardium throughout the lifetime of mammals.

\section{INTRODUCTION}

Current understanding defines the heart as an organ comprised of heterogeneous population of myocytes, which continue to die and self-renew, thereby maintaining cardiac integrity throughout life. However, the cell source for heart self-renewal, purportedly by the replacement of senescent cardiomyocytes (CMs) with juvenile cells, as well as the underlying mechanisms remain obscure. Dedifferentiation of adult CMs [1,2], transdifferentiation of endogenous stem cells (SCs) [3], and fusion of SCs with cells of other types [4] are usually considered as major scenarios whereby new CMs are generated in adult heart [5]. The concept of mature pre-existing CM division as 
well as proliferation and differentiation of resident cardiac stem cells (CSCs) are commonly regarded as potential mechanisms of cardiomyogenesis $[5,6]$. Along with above described mechanisms, the existence of small CM-like cells gaining the ability to contract within 3 days after plating has been demonstrated in cell culture experiments [7]. Moreover, hypoxia [8] and ischemia [9] have been shown to stimulate proliferation of rare small cardiac markerpositive cells, which are nonetheless unable to regenerate injured myocardium. These observations raise several important questions, including the origin of these small CM-like cells, their localization in healthy myocardium and their in vivo potential to regenerate injured myocardium. This issue merits special attention not only because of its importance for the understanding of basic mechanisms that govern myocardial self-renewal but also because of its clinical implications in cell-based therapy of myocardial infarction and chronic heart failure [10-12].

Our previous data obtained in in vitro newborn rat cardiac cell cultures showed conclusively that mature contracting CMs were generated during colony formation from resident CSCs of three subtypes, that is, c-kit ${ }^{+}, \mathrm{Sca}-1^{+}$ и Isl- $1^{+}[13]$. In addition, we described a phenomenon of intracellular development of CSCs inside mature CMs with the formation of «cell-in-cell structures» (CICSs) followed by the release of transitory amplifying cells (TACs), positive for CSC antigens and cardiac markers [14]. Since TACs released from the CICS are progressively enlarging, which is paralleled by their cardiomyogenic differentiation, these cells might be considered as precardiomyocytes.

To test the involvement of CSCs in these two pathways of cardiomyogenesis in mammalian heart, we characterized colonies and CICSs from a suspension of $e x$ vivo freshly isolated myocardium of mammals of different age and from different species, including humans. The presence of CSC-derived colonies and TACs, released from CSC-derived CICSs in all myocardial specimens, provided additional proof for our previous hypothesis about two principal pathways that generate new $\mathrm{CMs}$ in adult heart. Moreover, our data strongly suggest that CSC-derived TACs play a central role in self-renewal of myocardium throughout the lifetime of mammals.

\section{RESULTS}

Freshly-isolated myocardial cells were fixed, permeabilized, and stained using a set of antibodies against CSCs and cardiac antigens. The design of the experiments are shown in Figure 1. We utilized 6 simultaneous markers: antibodies to cardiac stem cell antigens (c-kit ${ }^{+}$, Isl- $1^{+}, \mathrm{Sca}_{-}{ }^{+}$) and cardiac proteins (Sarcomeric a-actinin or a-Sarcomeric actin and Troponin T), and Hoechst for
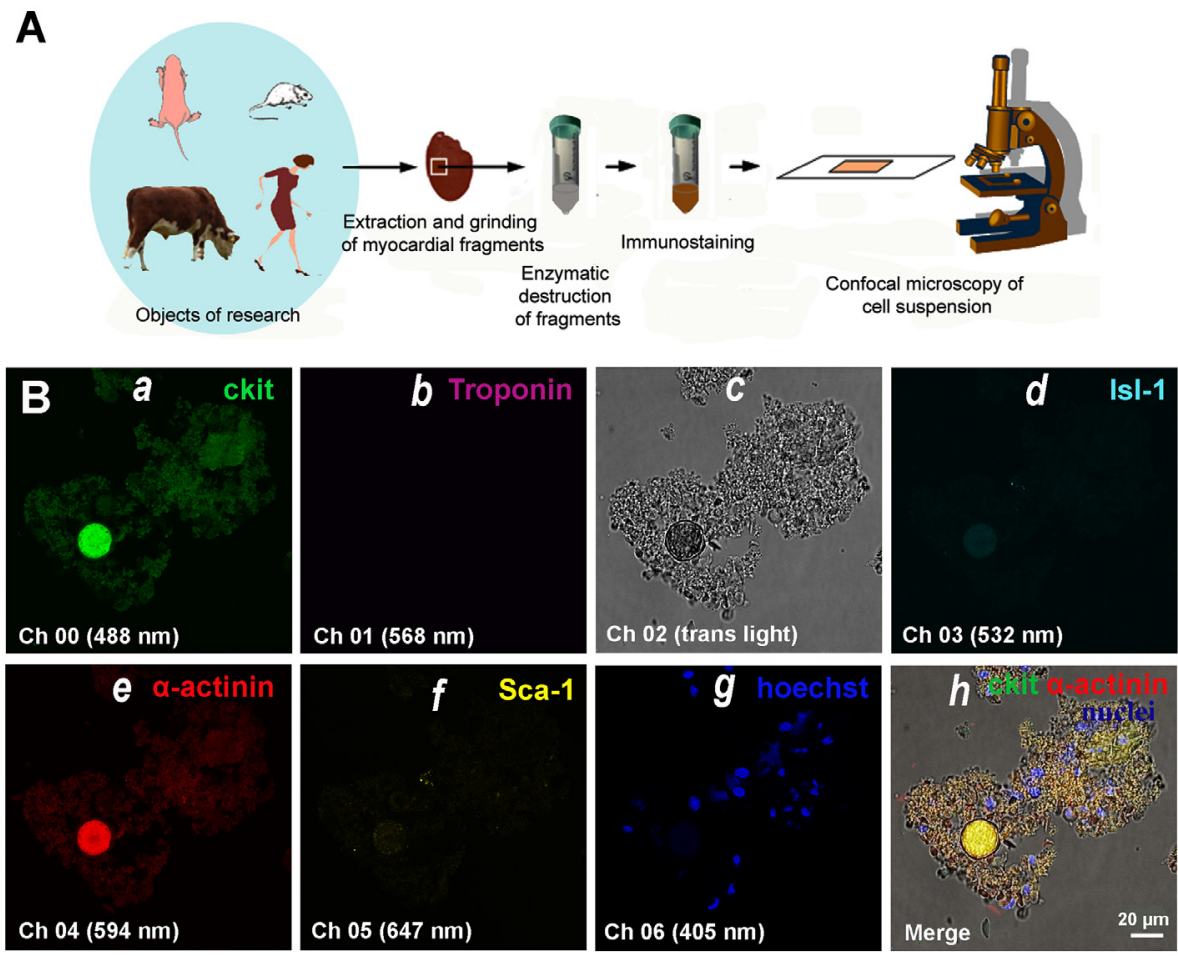

Figure 1: Experimental design. (A) Dissected hearts or myocardial fragments of mammals of different species and age were enzymatically dissociated into single cell and small fragment suspension. The enzyme-free cell suspension was stained using antibodies, followed by suspending the cells between the slide and cover slip. (B) Confocal microscopy of myocardial cells of 4.5-month-old rat. (a) c-kit+. (b) Troponin. (c) Transmitted light. (d) Isl-1+. (e) Sarcomeric $\alpha$-actinin. (f) Sca-1+. (g) Hoechst (nuclei). (h) Merged c-kit+, Sarcomeric $\alpha$-actinin, and Hoechst staining on transmitted light image. 
nuclear staining. The highest fluorescence brightness of one of three CSC markers at a single sample, as well as a positive expression of cardiac proteins, was allowed to define what type of CSCs have formed colonies or CICSs (see Materials and Methods, Figure 1B and Supplementary).

Ex vivo analysis of cell suspension showed that the formation of mature CMs via proliferation and differentiation of CSCs inside the colonies occurs in mammals of different age and different species, including humans. For example, a small colony of immature Sca$1^{+}$CSCs (Figure 2A) was identified in a fragment of myocardium derived from a 40-day-old rat, while large c-kit ${ }^{+}$colonies of various maturity were identified in adult rat myocardium. For example, the colonies were found to be more mature in 7-month-old rats (Figure 2B and Supplementary Figure 1) compared to 1.5-year-old rats (Figure 2C and Supplementary Figure 2). In the hearts of adult C57/b16N mice we also registered colonies of different level of maturity: an immature c-kit ${ }^{+}$colony with negligible numbers of CSCs (Figure 2D), a small poorly differentiated Isl- $1^{+}$colony (Figure $2 \mathrm{E}$ ) and a large highly differentiated Isl- $1^{+}$colony, positively stained for Sarcomeric $\alpha$-actinin (Figure $2 \mathrm{~F}$ and Supplementary Figure 3). Large poorly differentiated c-kit ${ }^{+}$colony positive to Troponin $\mathrm{T}$ was identified in the myocardium of one-year old steer (Figure 2G and Supplementary Figure 4). Besides, colonies of various sizes and maturity formed by CSCs of three different subtypes were found in the heart of 45-year-old woman (Figure 2H-2L and Supplementary Figure 5, 6). Given the fact that the length of human cardiomyocytes ranges from 50 to $150 \mu \mathrm{m}$, we consider the compact clusters of CSC-positive cardiac cells of different sizes and different degrees of differentiation as colonies of developing cardiomyocytes. For example, such colony is shown in Figure $2 \mathrm{H}$ and Supplementary Figure 5 , consisting from small undifferentiated c-kit ${ }^{+} \mathrm{CSCs}$ with diameters ranging from 5.4 to $19.7 \mu \mathrm{m}$, while cells inside the compact colony formed by Sca- $1^{+} \mathrm{CSCs}$ (Figure 2I and Supplementary Figure 6) are poorly differentiated and have $\mathrm{L}_{\text {mid }}=46.8 \pm 20.6 \mu \mathrm{m}$. CMs at the periphery of this colony were found to reach $84.7 \mu \mathrm{m}$ in length. The images on Figure 2J-2L represent colonies of different maturity, different expression of stem cell antigens and sizes of CMs in adult human heart. The length of cells in compact Sca$1^{+}$colony (see Figure $2 \mathrm{~J}$ ) range from $16.3 \mu \mathrm{m}$ to $67.3 \mu \mathrm{m}$ $\left(\mathrm{L}_{\text {mid }}=39 \pm 13 \mu \mathrm{m}\right)$, while the size of cells inside colony formed by c-kit ${ }^{+}$CSCs (Figure $2 \mathrm{~K}$ ) varies from $14.6 \mu \mathrm{m}$ to $68.6 \mu \mathrm{m}\left(\mathrm{L}_{\text {mid }}=29.9 \pm 17.7 \mu \mathrm{m}\right)$. In turn, mature $\mathrm{CMs}$ mildly expressing Isl- $1^{+}$antigen with $\mathrm{L}_{\text {mid }}=63.8 \pm 18.9$ $\mu \mathrm{m}$ and $\mathrm{L}_{\text {max }}$ reaching $98.4 \mu \mathrm{m}$ are shown in Figure $2 \mathrm{~L}$.

Along with identification and characterization of CSC-derived colonies in suspensions of myocardial cells from different mammalian species, we revealed "cell-in-cell structures" (CICSs) formed by c-kit"-, Sca-
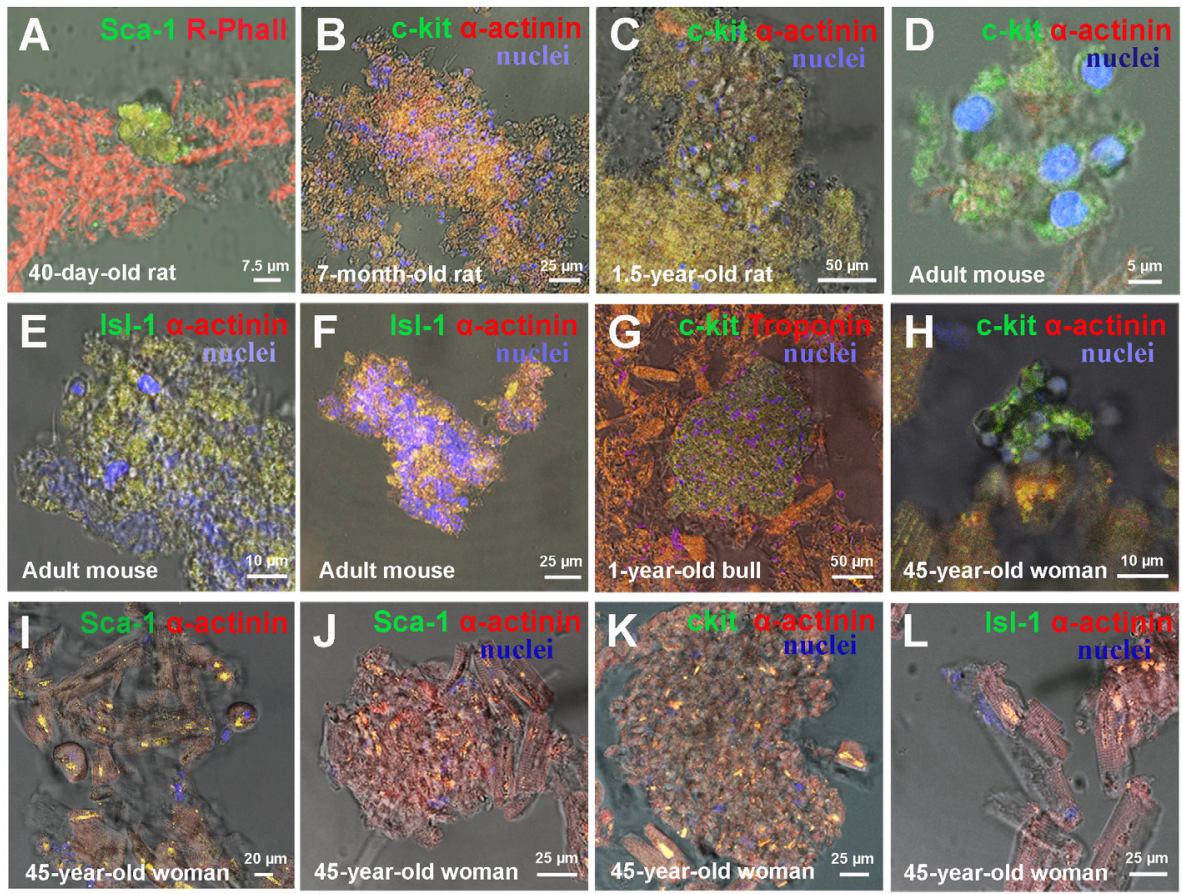

Figure 2: Ex vivo characterization of CSC-derived colonies in freshly isolated suspension of myocardial cells of Wistar rats, adultC57bl mouse and 45-years-old woman. (A) Small colony of 40-day-old rat Sca-1+ CSCs. (B) 7-month-old rat c-kit+ colony. (C) 1.5-year-old rat c-kit+ colony. (D) Adult mouse c-kit+ colony. (E) Adult mouse Isl-1+ colony. (F) Adult mouse Isl-1+ colony. (G) One-year-old bull c-kit+ colony. (H-L) 45-year-old woman colonies. c-kit+, Isl-1+, Sca-1+ (green). Rhodamin-Phalloidin,Sarcomeric $\alpha$-actinin, Troponin T (red). Nuclei (Hoechst), blue. 
$1^{+}$- and Isl- $1^{+}$subtypes of CSCs. It was seen that CICSs of different maturity have similar morphology with the presence of dense capsule and well-defined openings (pores) on its surface (Figure 3). The number of pores was found to vary from three in one-year-old steer (Figure 3E, Supplementary Video 1) and 45-year-old woman (Figure 3J, Supplementary Video 2) to four in 45-year-old woman (Figure 3I, Supplementary Video 3) and 40-day-old rat (Figure 4E (arrow), Supplementary Video 4). CICSs with three pores were characterized by spherical form (see Figure 3) while CICSs bearing four pores had more complex tetrahedral form (see Supplementary Video 3 and 4).

CICS sizes (length, width) ranged from 22.5 \pm 1.2 $\mu \mathrm{m}$ to $29.7 \pm 3.5 \mu \mathrm{m}$ with vertical dimension $10-41 \mu \mathrm{m}$. Notably, $\mathrm{D}_{\text {mid }}$ were almost identical in young and old mammals of different species, whereas the volumes demonstrated considerable variability from $6211 \pm 2185$ $\mu \mathrm{m}^{3}$ to $10704 \pm 3332 \mu \mathrm{m}^{3}$, with large standard deviations, which, however, are not statistically significant (Table 1). Moreover, there were no significant interspecies differences in morphology and size of myocardial CICSs compared to CICSs generated in primary culture (Table 2 ). The data presented in Table 2 show that the volume of CICSs produced over the period of 20 days in primary culture of myocardial cells obtained from newborn rats is similar to that of CICSs from the myocardium of juvenile, adult and old rats (Table 1). Moreover, the volume of CICSs was shown to be almost the same in all mammalian species investigated, taking into account the interspecies differences in cardiomyocyte dimensions.

The fact that maximum volume of intact CICSs did not exceed $15000 \mu^{3}$ with mean value of 8000 $\mu \mathrm{m}^{3}$ suggests that intracellular CSC development occurs in incompletely differentiated cardiac myocytes rather than in mature cardiomyocytes with volumes of more than $20000 \mu^{3}$ [5]. In cardiac cell culture of newborn rats, we previously observed the formation of either small immature colony or CICS in the vicinity of large differentiated colony (unpublished observation). In such a case, CICS was produced from the same type of CSC as the adjacent colony. These initial observations were further analyzed using confocal microscopy of freshly isolated myocardial cell suspension obtained from mammals of different age. Figure 4A-4D demonstrates the presence of small poorly differentiated yellow colonies on the surface of large, cardiac protein-positive (red staining) colonies of different maturity. CICSs were identified either on the surface of the mature colonies (Figure 1B and 4E) or inside the colony (Figure $4 \mathrm{~F}$ ) or in the vicinity of the colony (Figure 4G, 4H).

It is well accepted that SCs in general [15], and CSCs in particular [16], are able to undergo either symmetric or asymmetric division. Keeping this in mind,
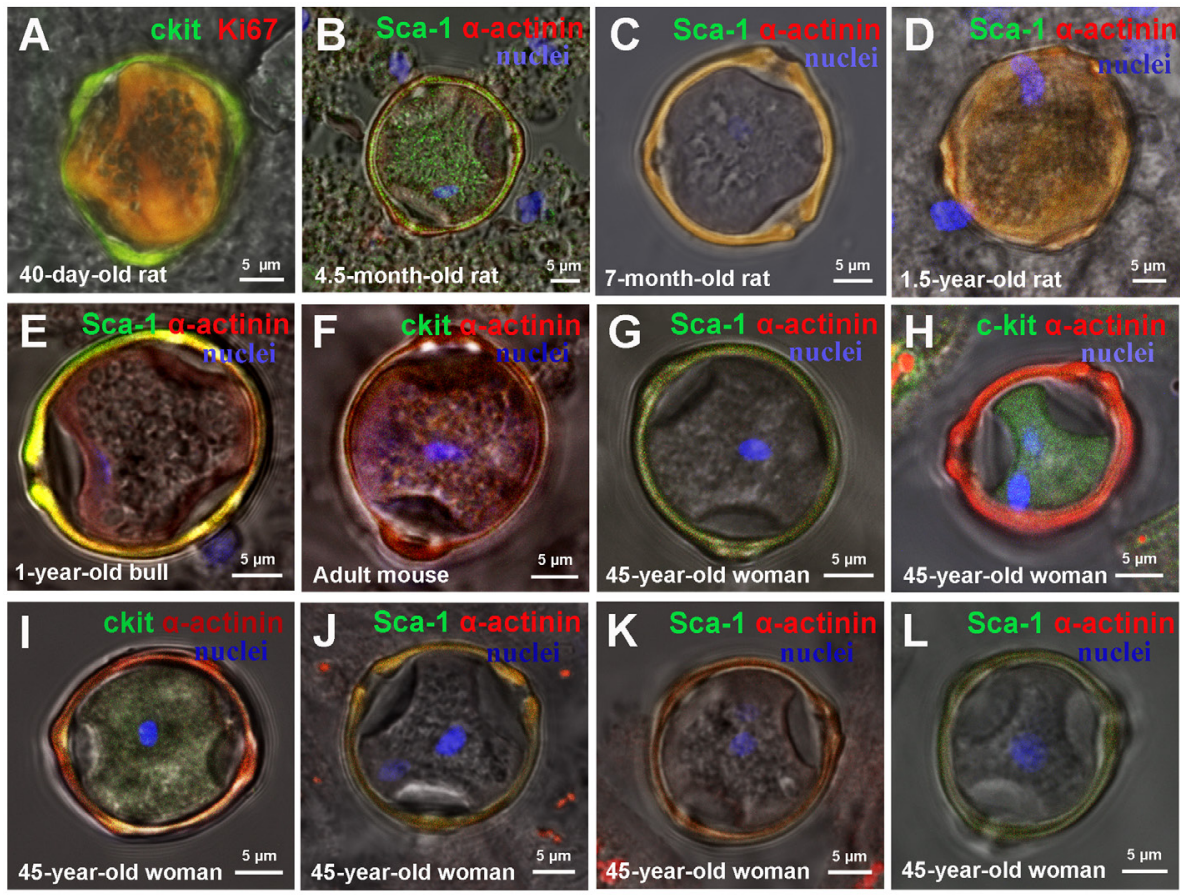

Figure 3: Types of cell-in-cell structures (CICSs) in a suspension of ex vivo freshly-isolated myocardial cells of mammals of different age and species. (A) 40-day-old rat c-kit+ CICS. (B) 4.5-month-old rat Sca-1+CICS. (C) 7-month-old rat c-kit+ CICS. (D) 1.5-year-old rat Sca-1+ CICS. (E) 1-year-old bull Sca-1+ CICS (See also Video 1). (F) Adult mouse c-kit+ CICS. (G-L) 45-year-old woman CICS (See also Video 2 and Video 3). c-kit+, Isl-1+, Sca-1+ (green). Ki-67-Phycoerythrin, Sarcomeric $\alpha$-actinin (red). Nuclei (Hoechst), blue. 
we suggested that asymmetric division of CSC results in the formation of colonies due to sequential divisions of single daughter committed cell. In this case, the other daughter cell retaining the "stemness" state might become activated only after certain time, giving rise to the new colony which is spatially close to the initial colony. It is evident that the secondary colony produced from the same type of CSC as the initial one, will have smaller size and lower level of differentiation, which is shown in Figure 4A-4D. It can not be ruled out, however, that daughter CSC will penetrate one of the cells comprising the colony to form CICS (Figure 4E-4H). Two important suggestions stem from these observations: (i) since the cells of CSCderived colony are still not fully mature and therefore are smaller than mature CMs, the size of growing CICSs is limited by their dimensions, and (ii) since the colony cells are in fact TACs, which start to differentiate and grow after several rounds of replication, the size of CICSs will increase in parallel to the size of TAC-derived maturating CMs.

Significant variability of CICS volumes both in ex vivo and in vitro experiments (Table 1 and 2, respectively) provide strong support for the hypothesis that this variability might be due to differences in the initial volume of host cell and progressive increase in volume during differentiation. Our previous in vitro experiments demonstrated that mean volume of cardiac cells during first 8-10 days of culture did not exceed $3246 \pm 190 \mu \mathrm{m}^{3}$ [13]. Table 2 shows that, apart from substantial variability in CICS volume (due to the thickness) there is also a tendency to increase in CICS volume with time. This lends support to the notion that host cell enlargement parallels the growth of CICS. As a result, typical CICS pattern is observed (Figure 3), with encapsulated CSCs occupying almost all space inside host cardiac cell. Moreover, this idea is indirectly confirmed by the fact that CSCs can sometimes penetrate CMs (Figure 5), and not only TACs.

For example, Figure $5 \mathrm{~A}$ demonstrates the residence of Isl- $1^{+} \mathrm{CSC}$ inside young CM from the myocardium of 1-day-old rat. This CM has the length (L) of $41 \mu \mathrm{m}$, while its width (W) is $16 \mu \mathrm{m}$ and $24 \mu \mathrm{m}$ in the narrow and wide portions, respectively. CSC-containing capsule $(\mathrm{L}=27$ $\mu \mathrm{m}, \mathrm{W}=18 \mu \mathrm{m}$, vertical dimension $=9 \mu \mathrm{m}$ ) with a pore on the upper pole (Figure 5A, white arrow) is localized in the upper part of the CM and occupies approximately $30 \%$ of CM volume. The capsule with a volume of 3600 $\mu^{3}$ was also identified inside the young CM having $40 \mu \mathrm{m}$ in length in the suspension of myocardial cells obtained from 4-day-old rat (Figure 5B). It is evident that both CICS and surrounding TACs display similar c-kit ${ }^{+}$ phenotype. In turn, mature $\mathrm{CM}\left(\mathrm{V}=10000 \mu \mathrm{m}^{3}\right)$ with Isl$1^{+}$bulging $(\mathrm{L}=24 \mu \mathrm{m}, \mathrm{W}=19 \mu \mathrm{m}$, vertical dimension $=19 \mu \mathrm{m}$ ) was earlier [14] identified in the myocardium of 20-day-old rat (Figure 5C). Despite well-developed sarcomeric structure, expression of $\alpha$-sarcomeric actin, this large $(\mathrm{L}=61.5 \mu \mathrm{m}) \mathrm{CM}$ is Isl-1-positive. The presence of capsule, though without dense wall (Figure 5C, black arrow), evolving pore (Figure 5C, white arrow) and small size are all suggestive of the fact that this "pregnant" $\mathrm{CM}$ demonstrates early stage of CSC development inside mature CM. The fourth specific structural pattern of CICSs discriminated on the basis of the analysis of more than 100 CICSs, was identified in the myocardium of 40-day-old rat (Figure 5D). This type of CSC-containing CICS has $\mathrm{L}=28 \mu \mathrm{m}, \mathrm{W}=15 \mu \mathrm{m}$, and thickness of $38 \mu \mathrm{m}$, which forms a capsule with volume of $7800 \mu \mathrm{m}^{3}$. Relatively small length, unusual shape, even distribution of cardiac $(\alpha$-Sarcomeric actin) and stem cell (c-kit) marker as
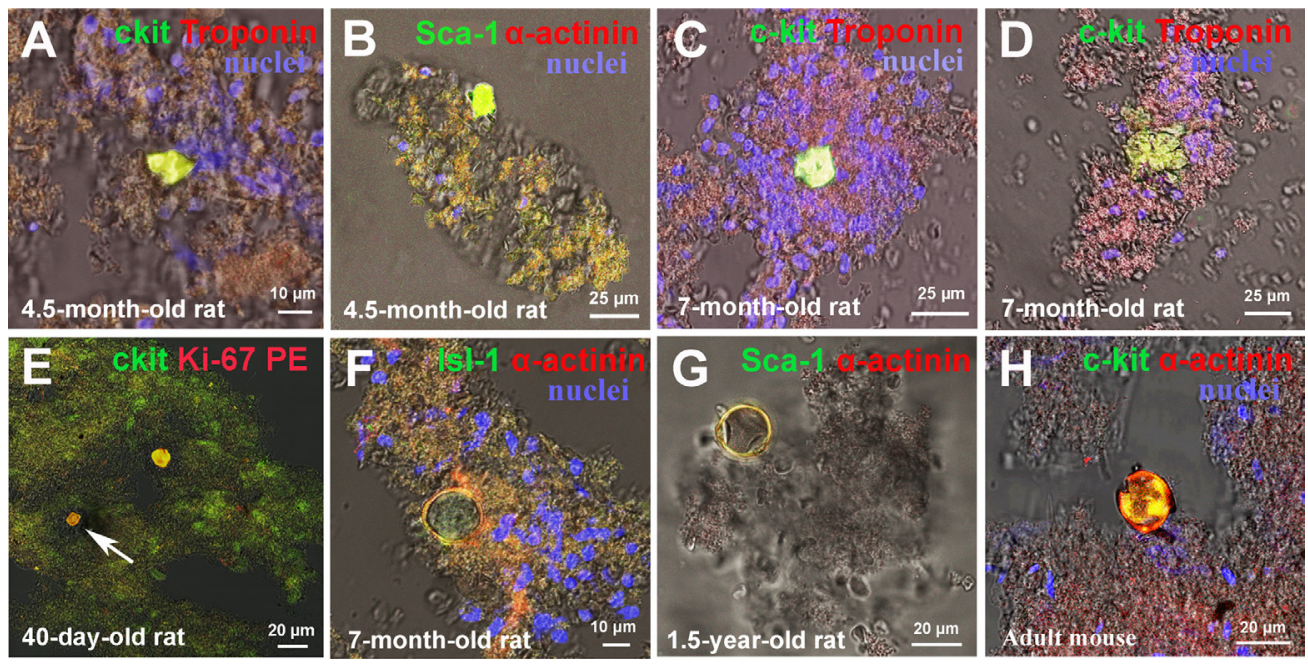

Figure 4: Ex vivo characterization of new colonies and cell-in-cell structures (CICSs) inside previously formed colonies. (A) 4.5-month-old rat c-kit+ colony. (B) 4.5-month-old rat Sca-1+ colony. (C) 7-month-old rat c-kit+ colony. (D) 7-month-old rat c-kit+ colony. (E) 40-day-old rat c-kit+ CICS (see also Video 4). (F) 7-month-old rat Isl-1+ CICS. (G) 1.5-year-old rat Sca-1+ CICS. (H) Adult mouse c-kit+ CICS. c-kit+, Isl-1+, Sca-1+ (green). Ki-67-Phycoerythrin, Sarcomeric $\alpha$-actinin, Troponin T (red). Nuclei (Hoechst), blue. 
Table 1: CICS parameters of mammals of different species and ages in ex vivo experiments

\begin{tabular}{lcc}
\hline Animals & $\mathbf{D}_{\text {mid }}(\boldsymbol{\mu m})$ & $\mathbf{V}(\boldsymbol{\mu m})$ \\
\hline 20-day-old rats & $25.8 \pm 0.3$ & $8258 \pm 1440$ \\
40-day-old rats & $26.1 \pm 2.5$ & $8469 \pm 3229$ \\
4.5 -month-old rats & $26.4 \pm 9.0$ & $6241 \pm 2720$ \\
7-month-old rats & $25.1 \pm 1.9$ & $7480 \pm 2480$ \\
1,5-year-old rats & $23.8 \pm 3.2$ & $7061 \pm 2997$ \\
1-year-old bull & $25.4 \pm 0.8$ & $8763 \pm 511$ \\
Adult mice & $25.1 \pm 2.0$ & $10704 \pm 3332$ \\
45-year-old woman & $22.2 \pm 1.5$ & $6211 \pm 2185$ \\
\hline
\end{tabular}

Table 2: The change of CICS sizes during 20 days in the culture of cardiac cells of newborn rats (in vitro)

\begin{tabular}{llc}
\hline Day In Vitro & $\mathbf{D}_{\text {mid }}(\boldsymbol{\mu m})$ & $\mathbf{V}(\boldsymbol{\mu m})$ \\
\hline $6-11$ & $26.3 \pm 7.2$ & $6972 \pm 3552$ \\
$16-20$ & $26.8 \pm 2.8$ & $9061 \pm 4598$ \\
\hline
\end{tabular}

The middle диаметр $\left(\mathrm{D}_{\text {mid }}\right)$ and the cell volume $(\mathrm{V})$ were calculated, using the following formula: $\mathrm{V}=3.14 / 6 \times \mathrm{L} \times \mathrm{W} \times$ vertical dimension. $\mathrm{D}_{\text {mid }}=(\mathrm{L}+\mathrm{W}) / 2$, where $\mathrm{L}-$ length, $\mathrm{W}$ - width.

well as the presence of 3 openings on both poles and in the constriction area (Figure 5D, arrows) led us to the suggestion that this structure results from invasion of c-kit ${ }^{+}$ CSC in partially committed to a cardiomyocyte lineage TAC. We suppose that despite relatively big initial size, the lack of mature sarcomeric structure allows this TAC to change its morphology, adjusting to the dimensions of invading CSC. More advanced cytoskeleton, seemingly, can interfere with this process leading to formation of such exceptional structure. Besides, since the volume of this structure corresponds well to the volume of average CICS (see Table 1 and 2), it might be suggested that intracellular development of CSCs is taking place not only in early TACs having length $\sim 10-13 \mu \mathrm{m}$ and volume $<4000$ $\mu^{3}$, but also in larger TACs, which are localized at the periphery of the colonies, establishing the contacts with mature CMs, as well as inside young CMs of relatively large size $(\mathrm{L}=40-60 \mu \mathrm{m})$ [13]. However, this scenario is observed extremely rarely.

As earlier in the culture of cardiac cells of newborn, 20-days-old and 40-days-old rats [14], ruptured CICSs and TACs released from them were present in suspension of myocardial cells of mammals of different ages and different species (Figure 6A-6H). It is necessary to emphasize that discovery of TACs in myocardial cell suspension at the stage when TACs are released from the capsule at the vicinity of ruptured CICSs and even at a certain distance from the ruptured CICSs (Figure 6A, 6E-6G) was possible because TACs develop in some mucous media inside CICSs. When released, TACs are submerged into this media
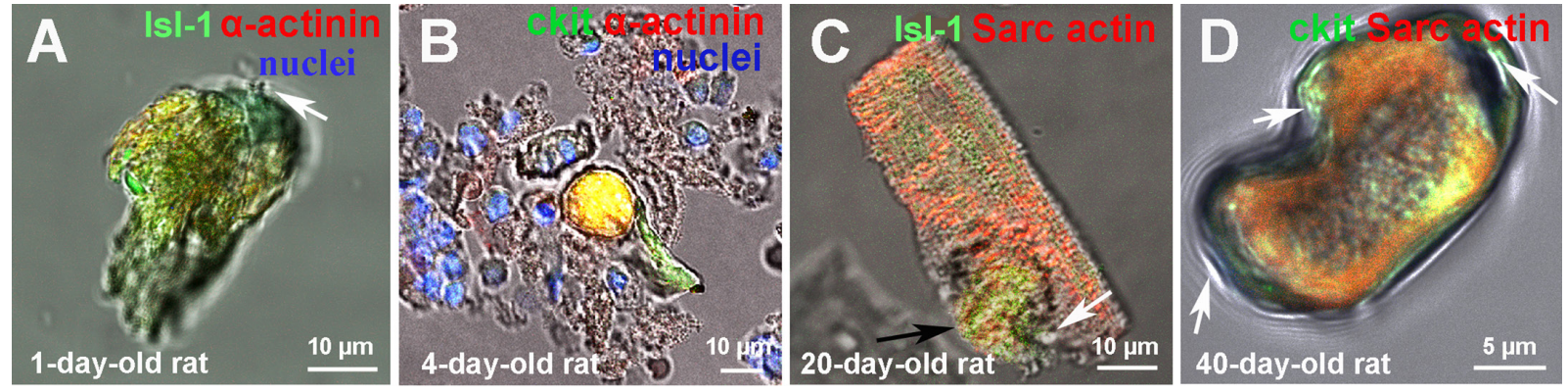

Figure 5: The examples of CSC development inside transitory amplifying cells (TACs) and young cardiomyocytes, revealed in a suspension of ex vivo freshly isolated myocardial cells of rats. (A) 1-day-old rat Isl-1+ CICS. (B) 4-day-old rat c-kit+ CICS. (C) 20-day-old rat Isl-1+ CM (reproduced from [14] with permission). (D) 40-day-old rat c-kit+ CICS. c-kit+, Isl-1+ (green). Sarcomeric $\alpha$-actinin, $\alpha$-Sarcomeric actin (red). Nuclei (Hoechst), blue. 
and reside there for some time. Similarly, this phenomenon was observed in our previous work, where mucous media and multiple TACs stuck together in vitro conditions [14]. Based on the situation shown at Figure $6 \mathrm{H}$ when multiple stuck TACs $(1=20-30 \mu \mathrm{m})$ and a single young CM (l=94 $\mu \mathrm{m})$ formed from the same type of CSCs $\left(\mathrm{Sca}-1^{+}\right)$, are located in close proximity to each other, we speculate that mucous media likely serves to restrain differentiation of TACs and to create a barrier to hinder penetration of signaling molecules of cardiac differentiation.

Despite the fact that antibodies against CSC antigens and cardiac proteins specifically bind to corresponding targets within CICSs, we failed to identify discrete cells inside CICSs. We hypothesized that the lack of CSC staining might be explained by intensive absorption of anti-CSC antibodies and Hoechst by highly viscous mucous media surrounding cells inside the vacuole [14]. Here we provide additional evidence supporting this hypothesis. Figure 7A clearly demonstrates diffusion of both antibodies and Hoechst into the vacuole. However, this is not accompanied by individual cell staining. Multiple small round-shaped structures inside the vacuole, presumably cell nuclei, remained colorless. Z-stacks of Sca-1-positive CICS (Figure 7B) support this notion, demonstrating only weak diffuse sarcomeric $\alpha$-actininpositive staining of mucous media and local presence of Hoechst in the central part of the vacuole $(z=9-13)$. Despite the obvious Ki67 diffusion into mucous media as evidenced by intense orange color, it also failed to stain
CSC nuclei inside the vacuole (Figure 3A). More detailed information about diffusion of antibodies and Hoechst into CICSs is provided in Figure 3A, 3F, and $3 \mathrm{H}$ (see Supplementary Figure 7). It should be noted that clear-cut staining of host cell nuclei by Hoechst shown in Figure $3 \mathrm{~F}-3 \mathrm{~L}$ is only possible because these nuclei are localized between the capsule wall and the membrane of host cell, thereby making nuclei more accessible for dye.

Additional experiments using two vital dyes (DiO and Dil) complemented by nuclear staining with Hoechst demonstrated that early stages of CICS development are characterized by the presence of small green cells with blue nuclei within the host cell stained red (Figure 8). Merge of figures shown on panels A and B (Figure 8D) clearly indicates that green cells are localized inside the host cell, which is accompanied by pushing away the cytoplasm of host cell to the periphery. Despite the fact that this structure could be visualized much better on Video 5, merging of all images (Figure 8F and Supplementary Video 5) makes it difficult to discriminate between the nuclei of muliple cells within the vacuole and the nucleus(i) of the host cell. Therefore, we performed special experiments with $\mathrm{DiO}$ and Dil dyes without accompanying nuclear staining with Hoechst. Using this protocol, we were able to visualize compact aggregation of small red cells inside larger host cell (Figure 9) and on Z-stacks of CICS (Video 6). Despite weak staining of host cell, green thickening on its membrane denotes the area of red cell penetration and further confirms that the
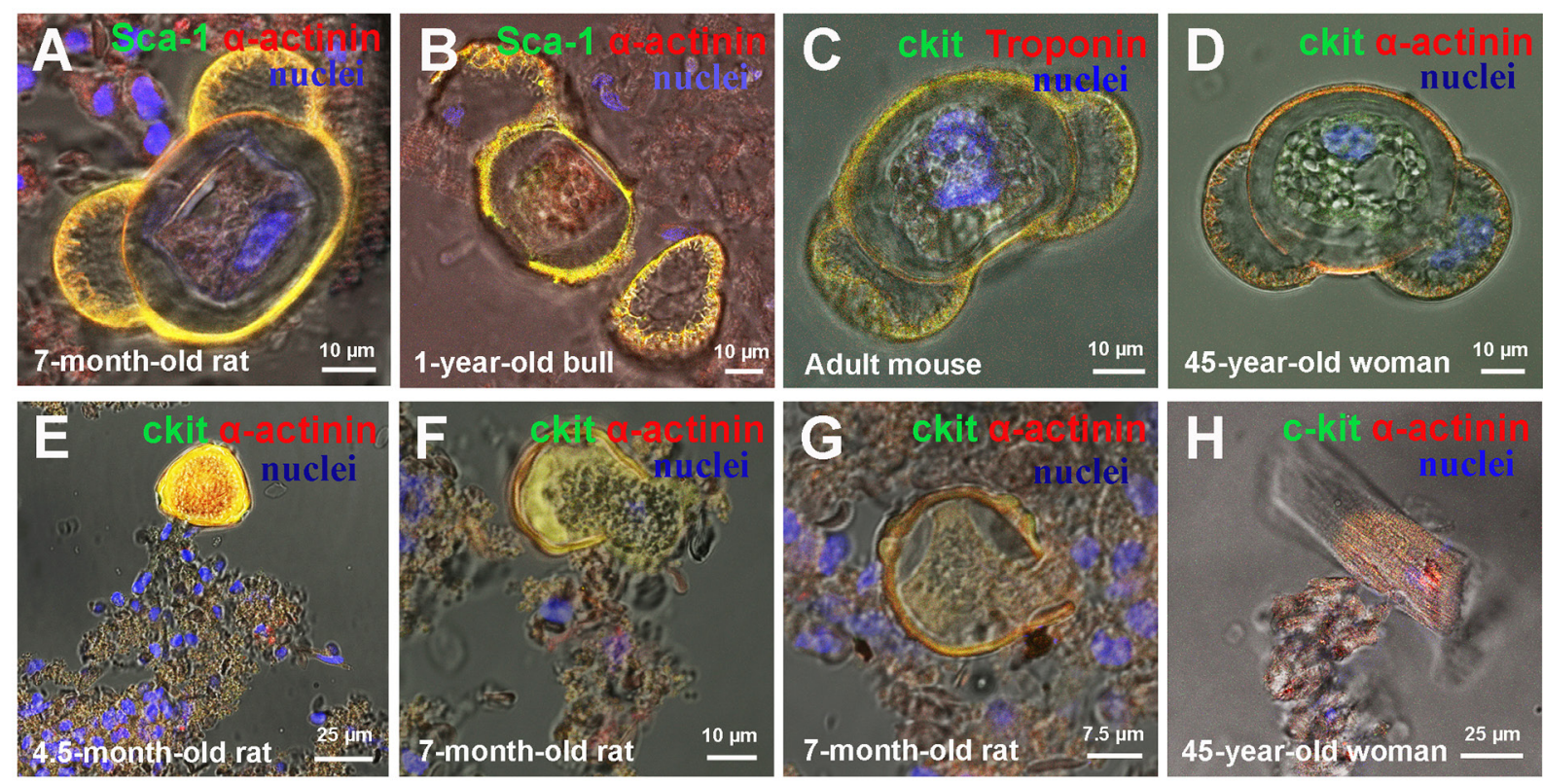

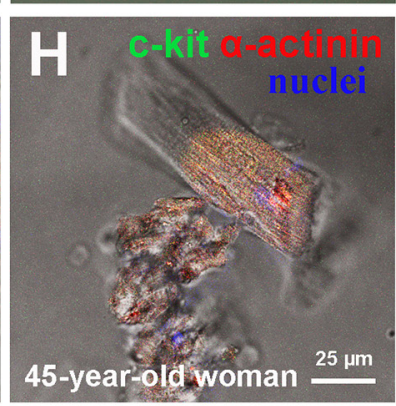

Figure 6: Rupture of cell-in-cell structures (CICSs) and release of transitory amplifying cells (TACs) in mammalian myocardium. (A) 7-month-old rat, Sca-1+. (B) 1-year-old bull, Sca-1+. (C) Adult mouse, c-kit+. (D) 45-year-old woman, c-kit+. (E) 4.5-month-old rat, c-kit+. (F) 7-month-old rat, c-kit+. (G) 7-month-old rat, c-kit+. (H) 45-year-old woman, c-kit+. c-kit+, Isl-1+, Sca-1+ (green). Sarcomeric $\alpha$-actinin (red). Nuclei (Hoechst), blue. 
membrane of host cell is stained green with DiO. These experiments showed that pre-stained cells were clearly visible inside the host cell at the early stages of CICS development. The open question is whether the cells could be stained inside mature CICS. This issue was explored using both $\mathrm{DiO} / \mathrm{Dil}$ and Hoechst for nuclear staining (Figure 10). Since DiO and Dil were used simultaneously, both stains marked the outer membrane of the host cell and diffused to the vacuole inside the capsule, while Hoechst readily stained host cell nuclei (arrows). It was also anticipated that the nuclei of cells within vacuole will become Hoechst-positive. However, the membranes and nuclei of the encapsulated cells were not clearly stained in analogy with the experiments on fixed samples stained with antibodies against stem cell and cardiac markers (see Figures 7A and 7B) and Hoechst. Thus, we presume that the lack of CSC staining within the mature CICS could be explained by the accumulation of viscous mucous media inside vacuole which prevents diffusion of antibodies and nuclear stains to their corresponding targets. Moreover, we suggest that mucous media performs two major functions: (i) it ensures protection of CSCs within the vacuole from exogenous harmful factors and (ii) it may contribute to cardiomyogenic differentiation of CSC progeny (TACs) because it can transport cardiac proteins from the sarcolemmal receptors of host cell, which appeared inside the vacuole during invagination of membrane together with CSC. It is critical to note that within the narrow space of the vacuole TACs acquire only initial cardiac differentiation while retaining the ability to proliferate.

Previously, we showed that CSCs from neonatal rat hearts generated colonies of contracting cardiomyocytes, imitating cardiomyogenesis in vitro by passing through several rounds of replication with subsequent differentiation into CMs [13]. This system can be used as an in vitro model system of myogenesis to test various compounds and factors, but is not suitable for assessment of the effects of age in proliferation capacities of CSCs and their ability to terminal differentiation in mammals and human.
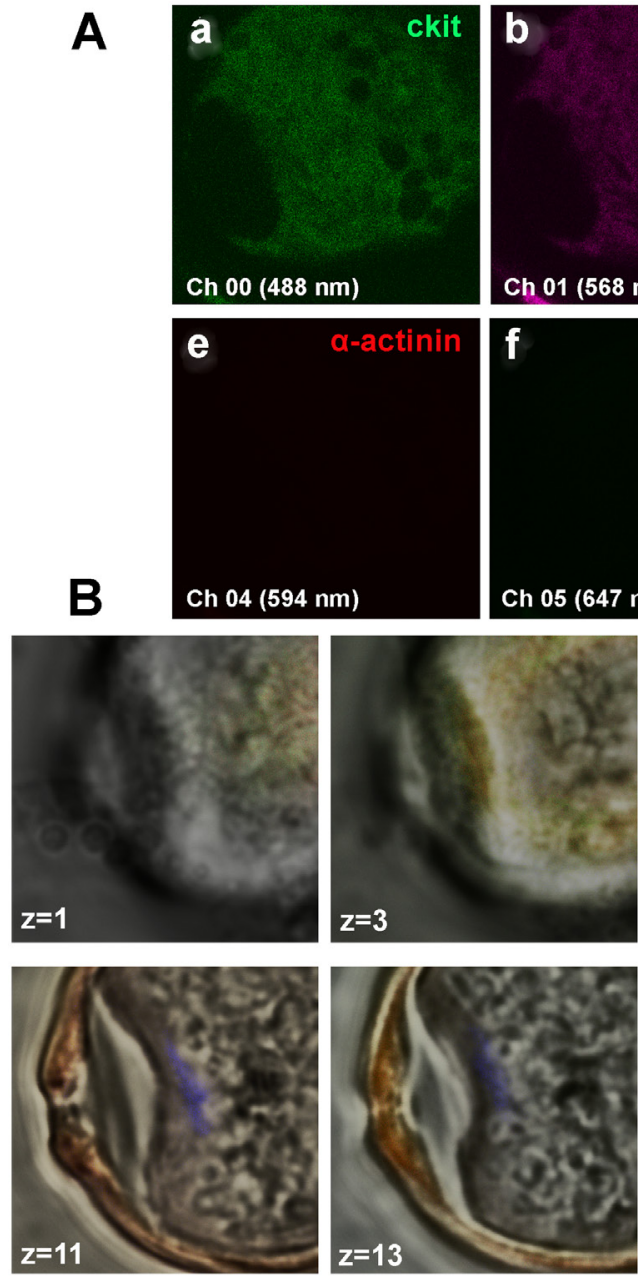
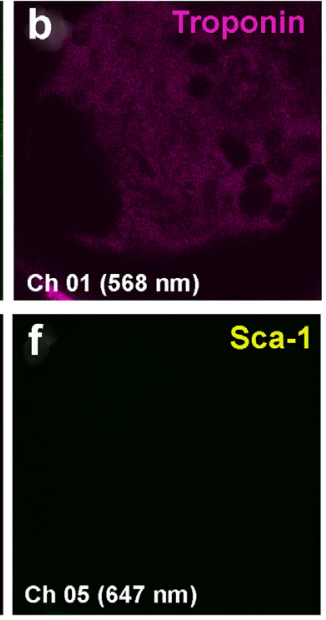
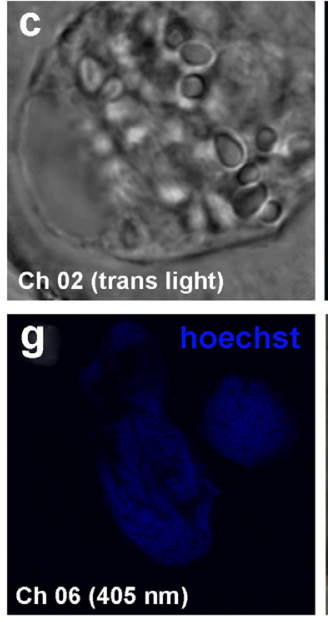
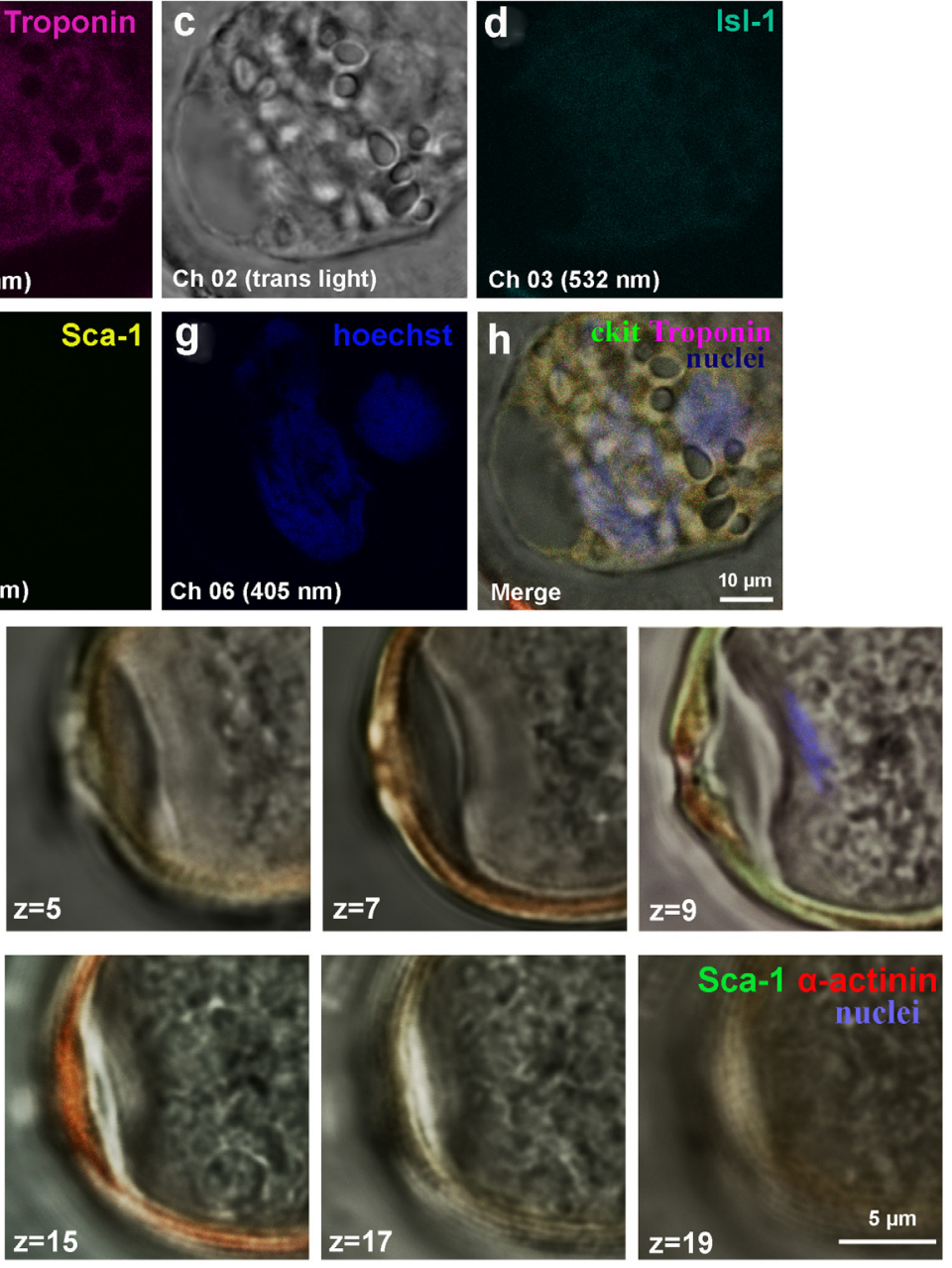

Figure 7: Confocal microscopy of CICSs of one-year-old bull. CICSs were stained with antibodies to cardiac stem cell antigens (c-kit+, Isl-1+, Sca-1+) and cardiac proteins (Sarcomeric a-actinin and Troponin T). Hoechst was used for nuclear staining. (A) Weak c-kit+ and Troponin expression along with the lack of Isl-1+ and Sca-1+ fluorescence is suggestive of the fact that CICS was produced by the penetration of cardiac myocyte by c-kit+ CSC. (B) Z-stacks of Sca-1-positive CICS. 
In this paper we pioneered to propose an ex vivo approach to assess activity of resident CSCs in myocardium of mammals by quantification of colonies and CICSs formed by CSCs. This approach helped us to identify CSC-derived colonies of different maturity, determine capacities of CSCs to self-renew myocardium of mammals of different age, and confirmed the phenomenon of intracellular development of resident CSCs in CMs with the formation of CICSs. In the previous work we described the process of CICS formation in primary myocardial cell cultures of newborn, 20-day-old and 40-day-old rats [14]. Here, we confirm the existence of CICSs in adult myocardium from different mammalian species and partly differentiated CSC-derived TACs which are released from ruptured CICSs after several rounds of replication inside the body of CMs.

There is a concept that the potential of myocardium to self-renew and regenerate diminishes throughout life
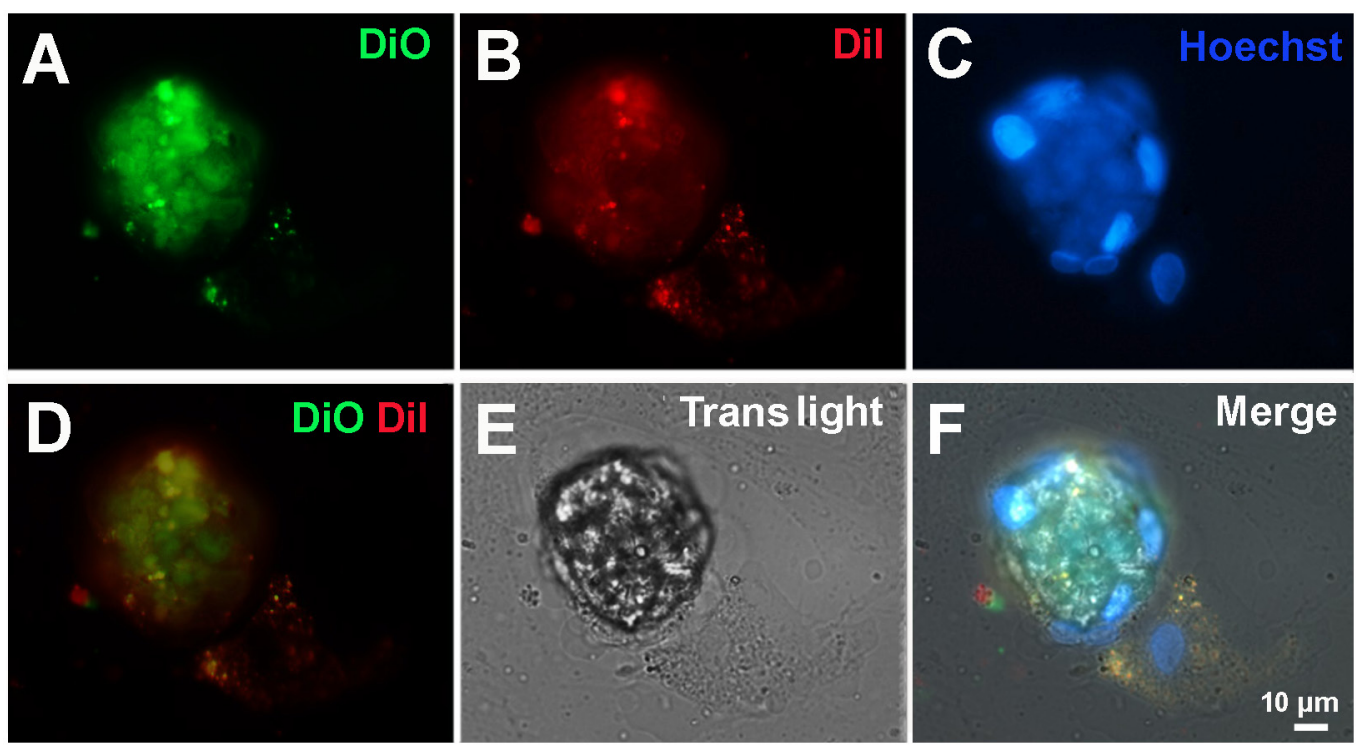

Figure 8: Fluorescent microscopy of CICS formed in the primary cardiac cell culture from 1-day-old rat on the 9th day in vitro. Cell membranes were stained by 2 vital dyes: DiO (green) and Dil (red). The nuclei were stained by Hoechst (blue).
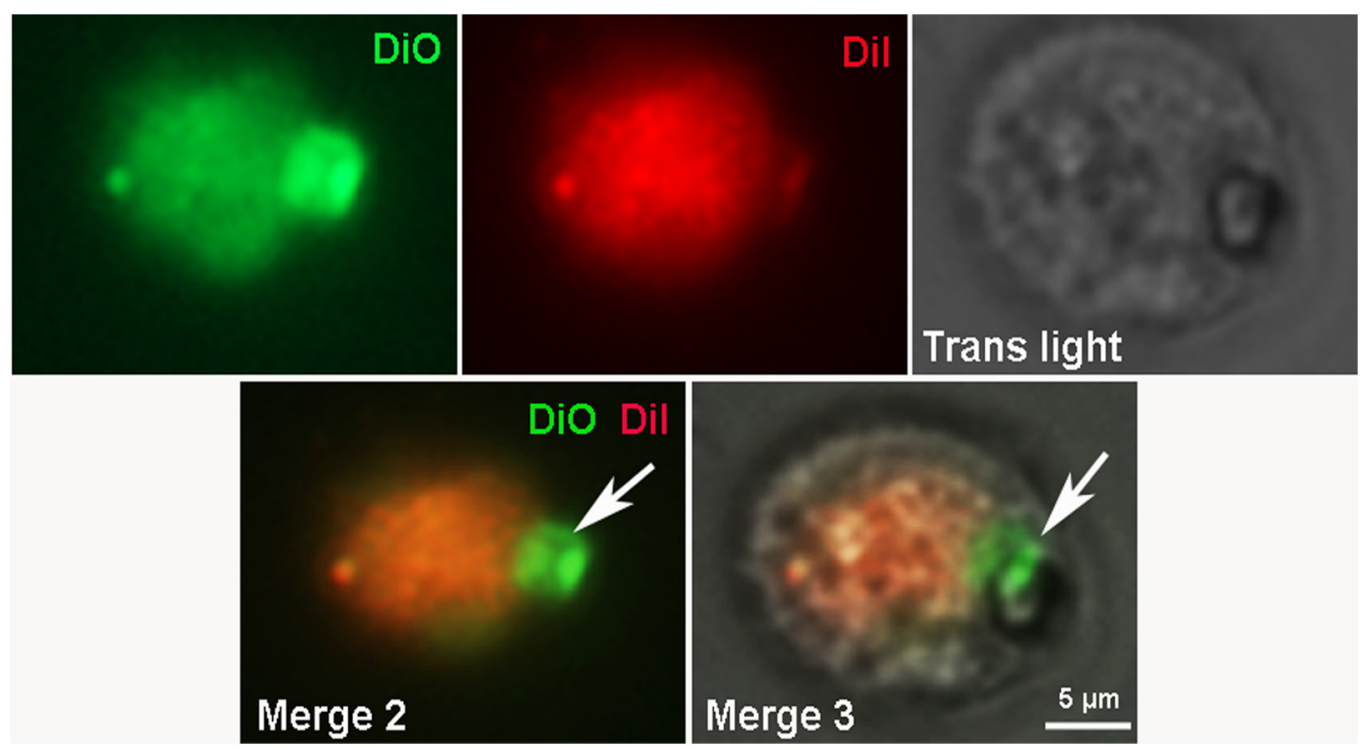

Figure 9: Fluorescent microscopy of CICS formed in the primary cardiac cell culture from 4-day-old rat on the 3rd day in vitro. Cell membranes were stained by 2 vital dyes: $\mathrm{DiO}$ (green) and Dil (red). 
[17] due to the reduced numbers of CSCs, decline in their functional activity [18] or because the sets of CSCs phenotypically become less diverse. Therefore, the role of different subsets of CSCs in colony formation and generation of CICSs in mammals of different age needs a close investigation. In this paper, we studied both processes in different mammalian species, including rat, mouse, steer, and human. In addition, we were interested to investigate whether CICS phenomenon is age-dependent. The third aim of the present work was to evaluate the contribution of c-kit ${ }^{+}, \mathrm{Sca}-1^{+}$and Isl- $1^{+} \mathrm{CSCs}$ to the formation of colonies and CICSs. In the study, all subsets of CSCs were found in mammals of different age. For example, Sca-1-positive colonies were shown to reside in myocardium of 40-day-old rats (Figure 2A) and a 45-year-old woman (Figure 2I, 2J). In turn, c-kit ${ }^{+}$ colonies were present in adult rats (Figure 2B, 2C), mice (Figure 2D), young bull (Figure 2G) and human (Figure $2 \mathrm{H}, 2 \mathrm{~K})$. At last, Isl-1-positive colonies were defined in myocardium of adult mice (Figure 2E, 2F).

Moreover, we showed that intracellular development with generation of CICSs in myocardium of adult mammals (rats, mice, bull and human) is relevant only for Sca- $1^{+}$and c-kit ${ }^{+}$CSCs subsets (See Figure 3). Sca- $1^{+}$ CICSs were present in 4.5-month-old rats (Figure 3B) and 1.5-year-old rats (Figure 3D), as well as in a 1-year-old bull (Figure 3E) and a 45-year-old woman (Figure 3G, $3 \mathrm{~J}-3 \mathrm{~L})$. c-kit ${ }^{+}$CICSs were identified in rats of different age (Figure 3A, 3C), adult mice (Figure 3F) and human (Figure $3 \mathrm{H}, 3 \mathrm{I}$ ). It is important to note that Isl- $1^{+}$CICSs occur in newborn and 20-day-old rats in vitro and ex vivo [14], but they were not identified in myocardium of older mammals and adult human. The data obtained on rats of different age are summarized in Table 3 . We can conclude that $\mathrm{c}-\mathrm{kit}^{+}$and $\mathrm{Sca}-1^{+} \mathrm{CSC}$ s produce both colonies and CICSs, thereby contributing to lifelong myocardial regeneration and self-renewal. However, Isl- $1^{+}$CSCs seem to be involved in cardiac growth during first month of age only both through colony formation and CICS generation. In turn, the studies on myocardial cell suspensions obtained from adult mice, one-year-old bull and 45-yearold woman not only confirmed the involvement of c-kit ${ }^{+}$ and Sca- $1^{+}$CSCs in both mechanisms of cardiomyogenesis in mammals of other species, but also showed that Isl- $1^{+}$ colonies are present in the myocardium of adult mice and as a rare event in human (see Table 4).

Our results for the role of $\mathrm{c}-\mathrm{kit}^{+}-\mathrm{CSCs}$ in cardiomyogenesis are consistent with data obtained in older rats by Beltrami et al. [19], in old mice and human by Bearzi et al. [20], Hosoda et al. [21], Anversa et al. [22], as well as with the data for Sca- $1^{+}$CSCs in young [23] and adult mice [24, 25] and human [26]. Despite the multiple facts about the presence of Isl- $1^{+}$CSCs in early postnatal period of rats and human [27] and in young and old rats [28], their existence in adult mammals and human has long been questioned [29]. In this study, we suggest that formation of mature CMs in adult mice occurs during colony formation from CSCs of different types, including Isl- $1^{+}$ones.

In addition, capsule rupture of CICSs is accompanied by the release of TACs, which are positive in different extent for the related CSC markers and cardiac proteins. TACs vary in size from $11 \mu \mathrm{m}$ to $113 \mu \mathrm{m}$ and have a gradually increasing expression of cardiac proteins which can be indicative of state of differentiation after the release from the ruptured CICSs. Similar morphology (Figure 3)
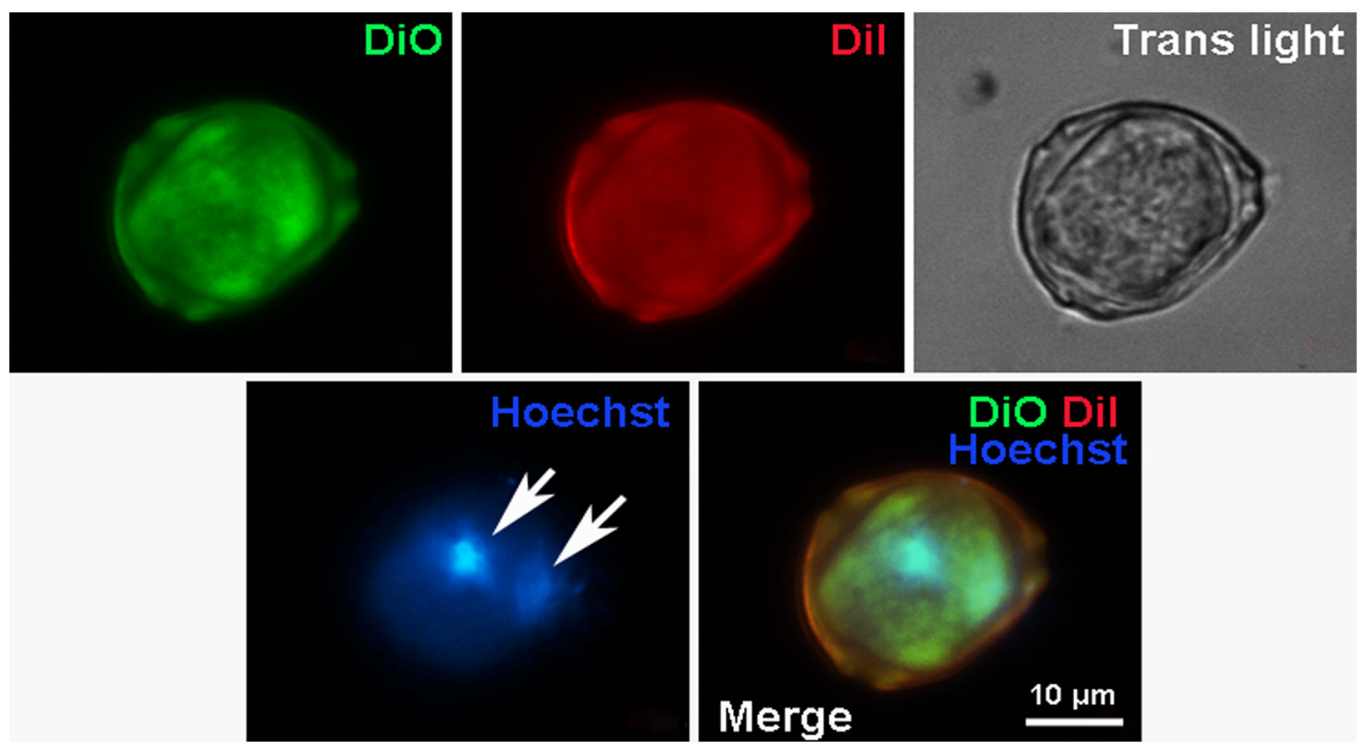

Figure 10: Fluorescent microscopy of mature CICS in the primary cardiac cell culture from newborn rat on the 6th day in vitro. Cell membranes were stained by 2 vital dyes: DiO (green) and Dil (red). The nuclei were stained by Hoechst (blue). 
Table 3: Participation of CSCs of various types in the formation of colonies and CICSs in the myocardium of differently aged rats

\begin{tabular}{|c|c|c|c|c|c|c|c|c|c|c|}
\hline \multirow{2}{*}{$\begin{array}{l}\text { Type of } \\
\text { CSC }\end{array}$} & \multicolumn{2}{|c|}{$\begin{array}{c}\text { Newborn } \\
\text { rats }\end{array}$} & \multicolumn{2}{|c|}{20 day-old rats } & \multicolumn{2}{|c|}{40 day-old rats } & \multicolumn{2}{|c|}{ 4.5-month -old rats } & \multicolumn{2}{|c|}{ 7- month -old rats } \\
\hline & colony & CICS & colony & CICS & colony & CICS & colony & CICS & colony & CICS \\
\hline c-kit ${ }^{+}$ & + & + & + & + & + & + & + & + & + & + \\
\hline Sca- $1^{+}$ & + & + & + & + & + & + & + & + & + & + \\
\hline Isl- $1^{+}$ & + & + & + & + & - & - & - & - & - & - \\
\hline
\end{tabular}

Table 4: Participation of CSCs of various types in the formation of colonies and CICSs in the myocardium of adult mammals

\begin{tabular}{|c|c|c|c|c|c|c|}
\hline \multirow[t]{2}{*}{ Type of CSC } & \multicolumn{2}{|c|}{ Adult mouse } & \multicolumn{2}{|c|}{$\begin{array}{l}\text { 1-year-old } \\
\text { bull }\end{array}$} & \multicolumn{2}{|c|}{$\begin{array}{c}\text { 45-year-old } \\
\text { woman }\end{array}$} \\
\hline & colony & CICS & colony & CICS & colony & CICS \\
\hline c-kit ${ }^{+}$ & + & + & + & + & + & + \\
\hline Sca- $1^{+}$ & + & + & + & + & + & + \\
\hline Isl- $1^{+}$ & + & - & - & - & $+/-?$ & - \\
\hline
\end{tabular}

and size of CICSs (Tables 1,2) in all experimental samples suggests that intracellular development of CSCs in CMs is a common biological event that occurs in mammals of different age and from different species. We assume that together with the formation of CSC-derived colonies, intracellular development of CSCs inside CMs might contribute to self-renewal and, possibly, to myocardial regeneration of mammals.

From the foregoing it follows that rat myocardium of several weeks after birth to very old rats contains CSCderived colonies of different maturity, as well as ruptured and unruptured CICSs of different size with the released TACs. Importantly, all investigated types of CSCs form colonies and CICSs in young mammals. In contrast, the major role in colony formation and generation of CICS is supposedly played by Sca- $1^{+}$and c-kit ${ }^{+}$CSCs in adult and old mammals.

\section{DISCUSSION}

Our results suggest that self-renewal of cells in mammalian myocardium is driven primarily by proliferation and differentiation of CSCs inside the colonies and by division and partial differentiation inside the bodies of small myocardial cells (TACs and young $\mathrm{CMs}$ ). Two processes of mature cardiomyocyte formation are schematically shown in Figure 11. The left side of the proposed scheme reflects the process of colony formation, while the right side depicts the stages of intracellular development of CSCs. We propose that the process of colony formation is associated with several rounds of CSC division, eventually resulting in formation of TACs with different level of differentiation. This occurs only when the colony is formed in contact with mature cells. The latter is a natural event both in vivo and in vitro, as was shown in our previous paper [13]. The last stage of this process is terminal differentiation of TACs with formation of mature CMs.

The process of intracellular development of CSCs has several distinctive features. First, CSC divides in an enclosed space inside the vacuole, which in turn is surrounded by the capsule inside mature CM. Capsule rupture is followed by the release of TACs partially differentiated into cardiomyocytes, which subsequently terminally differentiate after the mucous media is removed. In contrast to CSC-derived colonies, where TACs differentiate gradually with a part of the cells differentiating soon after division of the primary CSC, while another part continues proliferation, intracellular TACs are believed to have the same initially differentiated phenotype at the stage of their release from CICS which does not prevent further proliferation. As intracellular TACs preserve their capacity to divide, the number of cells capable to terminal differentiation into mature $\mathrm{CMs}$ can be increased several folds. As we described previously in vitro, ruptured CICS releases as many as 200 TACs [14]. Therefore, TACs released from just a single CICS after one or two rounds of cell division and subsequent differentiation can produce more than 400 new CMs.

In this regard it is of interest to consider CSC responses to hypoxia and ischemia. Switching cell culturing conditions the ones that mimic hypoxia and acidosis in injured myocardium helped us to directly interrogate behavior of CSCs similar to that in the infarct 
zone. For the first time we demonstrated that lowering medium $\mathrm{pH}$ to 5 and $\mathrm{O}_{2}$ concentration to $85 \%$ (hypoxia) blocks differentiation of CSCs inside colonies in cell cultures obtained from newborn rats. However, these deleterious factors stimulated intracellular development of all types of CSCs and enhancing the numbers of CICSs in 5-10 times compared to control.

Given the observation that imitation of ischemia and infarction in in vitro experiments suppresses colony formation, but significantly augments intracellular development of CSCs several folds, we suggest that stressful conditions in myocardium and, possibly, in the whole body, can shift the equilibrium between the two processes whereby mature CMs are formed. This suggestion is further supported by the results of our space project Bion-M1. Ex vivo investigation of immunocytochemically stained myocardial cells showed that the number of CSC-formed colonies of different maturity was significantly higher in the myocardium of mice subjected to 30-days space microgravity. It should be noted that the number of CICSs was not different from the control animals. Based on this data, we reasoned that weightlessness-induced loss in heart muscle weight is compensated by an increase in the activity of resident CSCs, which form new CMs inside the colonies. However, lack of hypoxia and inflammation in the myocardium during space flight did not stimulate of CSC development inside CMs.

Moreover, our results allow to suggest that passive participation of resident CSCs in regeneration of myocardium may be due to the switch of CSCs to the intracellular path of development when exposed to inflammation, rapid fibrosis, and circulatory failure in myocardial infarction [30]. It is plausible that stressful conditions force CSCs to hide inside mature CMs. However, even under optimal conditions, development of CSCs inside CMs with the following generation of CICSs is 2-2.5 times longer in time compared to the formation of differentiated CMs inside the colonies: 20-25 days vs 10-11 days, respectively. Therefore, suppression of colony formation and a switch of CSCs to intracellular path of development during ischemia and infarction can substantially reduce or even completely rule out the role of CSCs in myocardium regeneration in an acute phase of

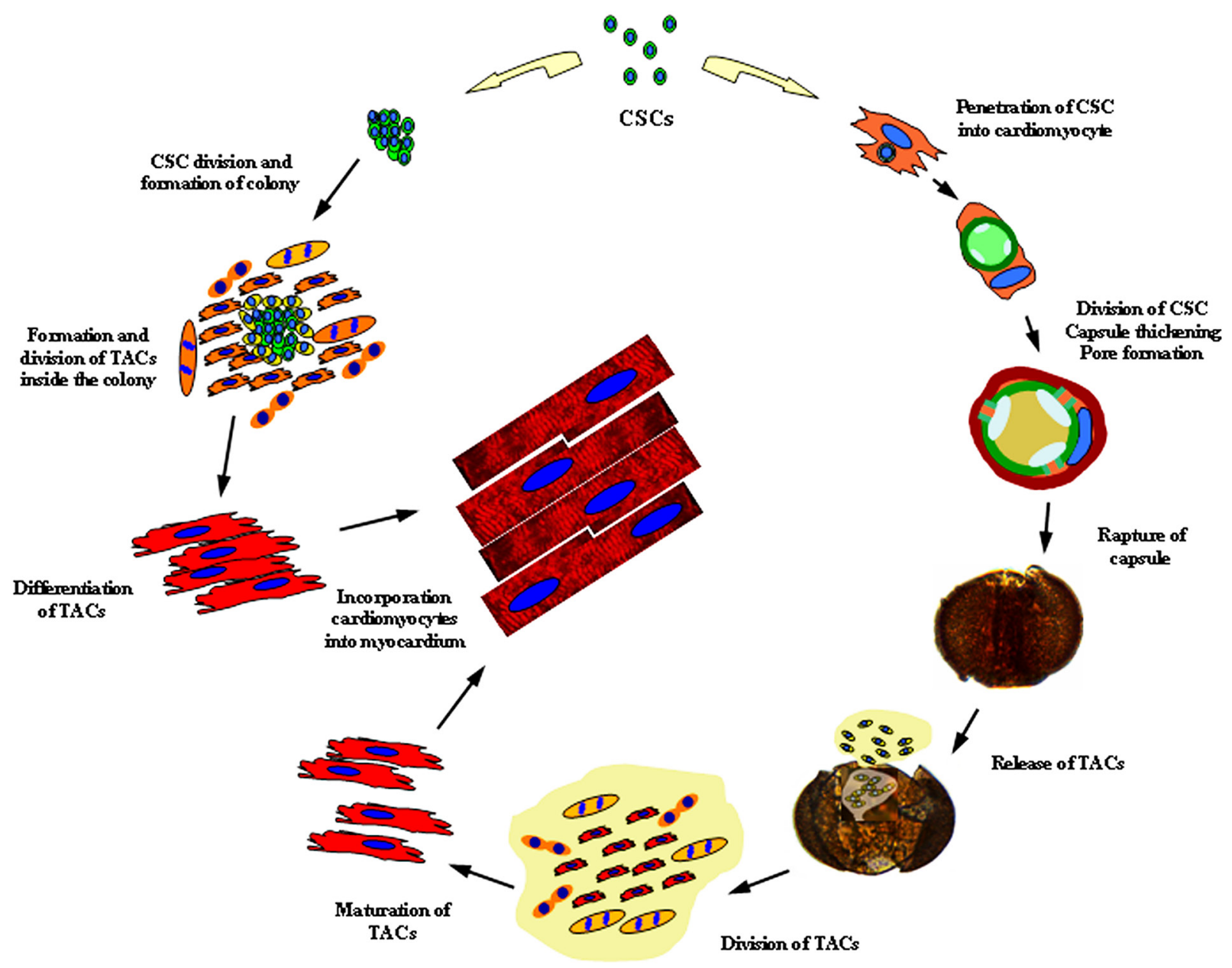

Figure 11: Schematic illustration of two pathways whereby mature CMs are generated from CSCs in mammalian myocardium. For details, see text. 
disease. It is fairly possible that stressful conditions nullify the effects of endogenous SCs as well as of exogenous $\mathrm{SCs}$, including pluripotent SCs and iPSCs, injected into damaged myocardium [31]. However, contribution of TACs released from CICSs in regenerative processes at later stages post-infarction and in chronic heart failure can be essential.

In the context of our hypothesis, it is necessary to discuss another crucial question on the agenda of cardiology: what kind of cells (resident CSCs or mature $\mathrm{CMs}$ ) renew adult myocardium? Recent papers where myocardium of mammals was found to contain small cardiac-positive cells with an ability to divide are of particular interest. For instance, Omatsu-Kanbe et al. [7, 32 ] described a population of small cells $(\sim 10-18 \mu \mathrm{m})$ in myocardium of adult mice, differentiating into contractile CMs without prior division in in vitro conditions. In turn, Kimura et al. [8] showed at mice myocardium that hypoxia induces formation of small dividing cells with characteristics similar to that of neonatal $\mathrm{CMs}$, i.e. a small size $(\sim 10 \mu \mathrm{m})$, mononuclearity and minor oxidative DNA damages. Based on this data, the authors suggest that there are neonatal-like CMs in myocardium of adult mammals with a capacity to proliferate not only at the first days after birth, but through the life-time. Moreover, recent data from Tang et al. [9] prove that 90-minutes ischemia with the following reperfusion and injection of allogenic c-kit ${ }^{+} \mathrm{CSCs}$ stimulates a prolonged proliferative response of endogenous a-Sarcomeric actin-positive cells that do not have a phenotype of mature CMs. Considering the fact that division of large $\left(>20000 \mu \mathrm{m}^{3}\right)$ and terminally differentiated CMs is doubtful or even denied [5], and small dividing cells exceed resident CSCs in size, the source and physiological role of these cells remains obscure.

Our results overarch recent data and point to the possibility that TACs released from the intracellular capsule of CICSs in our studies represent CMs of the «new type» described by Omatsu-Kanbe, et al. [7, 32] as well as small immature neonatal-like CMs, produced in hypoxia [8] and ischemia [9]. In the former paper [7] the authors transferred the supernatant obtained by centrifugation of a suspension of adult mice myocardial cells (light fraction) into cell culture. To our understanding, this fraction always contains TACs released after the rupture of mature CICSs. In the paper by Kimura et al. [8] neonatal-like CMs produced in hypoxic conditions are very similar to cells obtained during stressful conditions stimulating the intracellular development of CSCs in our in vitro studies. In addition to that, our data on CSCs hiding inside mature CMs under stressful conditions suggest that aSA-positive small cells observed by Tang et al. [9] after occlusion of the aorta could have been transitory amplifying cells released from CICSs, as shown in our experiments.

Because of none of the abovementioned papers consider small neonatal-like CMs to be derived from a stem cell source, it is important to underscore that expression of stem cells antigens gradually declines during intracellular development in the descendants of the parental CSC. At the same time, synthesis of cardiac proteins (a-sarcomeric actin, sarcomeric a-actinin, troponin $\mathrm{T}$ ) increases. This particular observation makes them attributable neither to CSCs, nor to a population of mature cardiomyocytes. TACs have a transitory phenotype, characterized by a larger size compared to CSCs (10-18 $\mu \mathrm{m}$ vs 5-6 $\mu \mathrm{m})$, varying levels of cardiac protein expression, weak or extremely weak properties of stem cells, but a preserved ability to divide. Not surprisingly, the source of small dividing cardiacpositive cells has remained unexplained out of the context of intracellular development phenomenon. In addition, proliferative capacities of TACs can be considered as the primary source of regeneration in myocardium of adult mammals. We hypothesize that these cells can not only support homeostasis of the heart by executing the processes of self-renewal throughout the whole life of the organism, but also to partially contribute to cardiac regeneration in post-infarct stage of disease or in chronic heart failure. This assumption is in good agreement with the view of Malliaras et al. [33], which using an inducible genetic labeling approach identified small $(11.5 \pm 3.7 \mu \mathrm{m})$ nonmyocyte cells expressing cardiac markers which they named cardioblasts. Besides, the authors have found that endogenous cardioblasts are rarely observed in the normal adult mouse heart, whereas their number is becoming tenfold increased after myocardial infarction. In addition, genetically labelled cardioblasts were shown to express cardiac transcription factors and sarcomeric proteins, demonstrated spontaneous contractions and gave rise to mature CMs after intramyocardial injection in vivo. It was unequivocally shown that these "endogenous cardioblasts" do not arise from hematogenous seeding, cardiomyocyte dedifferentiation, or just expansion of a preformed progenitor pool [33].

It is surprising that despite the availability of data on the residence of small proliferating cells with cardiomyogenic potential in the adult heart, many authors [34-37], including those who described "endogenous cardioblasts" [33], continue to believe that proliferation of pre-existing cardiomyocytes is the dominant mechanism for generation of CMs in adult mammalian myocardium. The ignorance of sharp contrast between the sizes of proliferating cells and mature CMs results in futile attempts to develop various ways of stimulating proliferation of pre-existing cardiomyocytes. It is clear that the impact of TACs and other types of cardiac-positive small cells (neonatal-like $\mathrm{CMs}$ or cardioblasts) on the heart in acute myocardial infarction needs to be determined. Moreover, precise investigation of their role in heart homeostasis of mammals will pave the new way for cell-based tools in regenerative medicine. 


\section{MATERIALS AND METHODS}

\section{Animals}

Wistar rats of different ages, 19-20-week-old C57/ bl6N mice and one-year-old bull were used throughout the study. The experiments were performed in accordance with the Guide for the Care and Use of Laboratory Animals and were approved by a local Ethics Committee.

\section{Mice}

The experiments were approved by the local Ethics Committee at the Institute of Mitoengineering, Moscow State University and the Institute of Medical Biological Problems, Russian Academy of Sciences. Male C57/ bl6N mice of SPF category were purchased from animal breeding facility at Shemyakin-Ovchinnikov Institute of Bioorganic Chemistry (Pushchino, Russian Federation). The animals were maintained on a $12 \mathrm{~h} \mathrm{light/dark} \mathrm{cycle}$ and were provided food and water ad libitum. The animals were euthanized by cervical dislocation performed by the experienced researcher.

\section{Rats}

The animals were euthanized by asphyxiation in $\mathrm{CO}_{2}$ chamber, after which organ samples were taken.

\section{Cattle}

Myocardial sample has been taken from 1-year-old steer at the farm immediately after killing.

\section{Human}

A fragment of human myocardium was isolated from a 45-year old woman post mortem, who died not due to cardiac disease or cardiac injury. Bioptic specimen was taken after the written informed consent was obtained from patient's relatives. The investigation conformed to the principles outlined in the Helsinki Declaration and was granted by the local ethics committee.

\section{Isolation of cardiac cells for ex vivo experiments}

Dissected hearts or myocardial fragments were enzymatically dissociated into a single cell and small fragment suspension as previously described [14]. Briefly, the hearts were excised and rinsed in Ringer's solution $(\mathrm{pH}$ 7.4) consisting of $146 \mathrm{mM} \mathrm{NaCl}, 5 \mathrm{mM} \mathrm{KCl}, 2 \mathrm{mM} \mathrm{CaCl} 2$, $1 \mathrm{mM} \mathrm{MgCl} 2,11 \mathrm{mM}$ glucose, and $10 \mathrm{mM}$ HEPES. After mincing and incubation in the same solution with the addition of $1 \mathrm{mg} / \mathrm{mL}$ collagenase IA (Sigma-Aldrich, USA) and $0.12 \%$ trypsin (FLUKA, Sigma-Aldrich) at $37^{\circ} \mathrm{C}$ for $30 \mathrm{~min}$, the suspensions thus obtained were left to rest without further stirring for 2-3 min to precipitate the undissociated tissue fragments. The supernatant was centrifuged at $400 \times \mathrm{g}$ for $10 \mathrm{~min}$ for the enrichment of viable cells. Gentle pipetting and centrifugation were used to preserve the integrity of myocardial CSC-derived colonies and CICSs. The enzyme-free cell suspension was stained using antibodies, followed by suspending the cells between the slide and cover slip.

This particular technique of cell isolation was used because we aimed to maintain the integrity of specific cellular structures, including CSC-derived colonies and CICSs, which are not identifiable with use of other approaches. Given rare occurrence of CSC-derived colonies and CICSs ( 1 colony or CICS per 100000 $\mathrm{CMs}$ ), we were as yet unable to identify and describe these structures using FACS analysis, confocal or electron microscopy of myocardial specimens. In this regard, the presented technique of ex vivo characterization of freshly isolated mammalian myocardial cells seems to be optimal for identification of previously unknown CICSs and CSCderived colonies of different size and maturity,

\section{Immunocytochemistry}

After rinsing with PBS and fixation for $20 \mathrm{~min}$ in $2.5 \%$ paraformaldehyde at room temperature, the cells were permeabilized with $0.25 \%$ Triton-X100 for $10 \mathrm{~min}$. For immunostaining we used primary mouse anti-Isl-1 antibodies (Abcam) and mouse antibodies to sarcomeric alpha-actinin (Abcam), alpha-sarcomeric actin (SigmaAldrich) and cardiac troponin $\mathrm{T}$ (Abcam) pre-conjugated with Alexa 532, 546, 568, 594, or 647 according to Zenon technology (Invitrogen). Phycoerythrin-conjugated anti-Ki-67 antibodies were used for determination of proliferative capacity of CSCs. Commercially available FITC-conjugated anti-c-kit (Abcam) and anti-Sca-1 (Abcam) antibodies were also used at 1:100 dilution. Hoechst $33342(10 \mu \mathrm{g} / \mathrm{mL}$, Molecular Probes, USA) staining at 1:1000 dilution was used for detection of cell nuclei.

Confocal microscope Leica TCS SP5 provides an opportunity to simultaneously analyze several fluorescent tags in wide spectrum (from ultraviolet to infrared), thus it is possible to use several fluorochromes and visualize expression of CSCs markers of several types at a single sample. Intensity of the corresponding fluorochrome serves to establish a type of CSC which generated a colony or CICS.

\section{Experiments with lipophilic membrane fluorescent dyes Dil and DiO}

Fluorescent membrane dyes Dil (Ex/Em - 549/565 $\mathrm{nm}$, Molecular Probes, Eugene, USA) and DiO (Ex/Em $484 / 501 \mathrm{~nm}$ ) were used to stain the membranes of living myocardial cells in red and green color, respectively. For this purpose, freshly isolated suspension of cardiac cells 
from newborn rats was divided into two fractions, one of which was incubated with $\mathrm{DiO}$ and another - with Dil for $20 \mathrm{~min}$ at $37^{\circ} \mathrm{C}$. After that, the cells were precipitated at $400 \mathrm{~g}$ for $10 \mathrm{~min}$ with subsequent washout from fluorophores. This was followed by combination of both fractions in warm DMEM supplemented with $10 \%$ fetal calf serum (Biovitrum, Russia), $50 \mathrm{U} / \mathrm{ml}$ of penicillin, and $50 \mu \mathrm{g} / \mathrm{ml}$ of streptomycin (Biolot, Russia). The cells were incubated with Hoechst 33258 (Ex/Em - 352/461 nm) at concentration of $3 \mu \mathrm{M}$ for $15 \mathrm{~min}$ under room temperature. This approach allowed to visualize both host cell and CSC nuclei. After removal of Hoechst, Dil/DiO-stained cells were plated onto the glass bottom dishes with collagen coating (MatTek Corporation) and incubated at $37^{\circ} \mathrm{C}$ according to previously reported protocol [13].

\section{Visualization}

A confocal microscope (Leica TCS SP5, Germany) with $20 \times$ and $63 \times$ glycerol objectives was used to visualize cells. For optical tomography, the sections were spaced $1.01 \mu \mathrm{m}$ along the $\mathrm{z}$-axis. Live myocardial cells stained with DiO, Dil, and Hoechst were visualized using inverted fluorescent microscope (Axio Observer.Z1, Carl Zeiss, Germany).

\section{Cytometry}

Linear cell dimensions were obtained using commercially avaliable software for confocal microscope (Leica TCS SP5) and were used for calculation of cell volume (V) using the following formula: $\mathrm{V}=3.14 / 6 \times \mathrm{L}$ $\times \mathrm{W} \times$ vertical dimension.

\section{Statistical analysis}

All of the data are expressed as the mean \pm standard deviation. The statistical analyses were performed using the SPSS 13.0 software package (SPSS Inc. Software, USA).

\section{Author contributions}

GB performed all experiments, analyzed and interpreted the data, performed the statistical analysis, and wrote the manuscript; $\mathrm{MG}$ analyzed and interpreted the data, helped to draft the final manuscript and added important comments to the paper; IN helped to perform experiments. All authors read and approved the final manuscript.

\section{ACKNOWLEDGMENTS}

Confocal microscopy were performed at the Research Resource Center «Molecular and Cell Technologies» of St-Petersburg State University.

\section{CONFLICTS OF INTEREST}

The authors declare no conflicts of interest.

\section{FUNDING}

This work was supported by the grants from the Russian Foundation for Basic Research (No 12-0400941 and 16-04-01424), Program of Presidium of Russian Academy of Sciences "Fundamental Sciences for Medicine" (2012-2014), by the state assignment of FASO of Russia ("The mechanisms of development of neuropsychic, metabolic and hormonal dysfunctions in the nervous and endocrine diseases and the approaches for their correction") and by Government of Russian Federation, Grant 074-U01.

\section{REFERENCES}

1. Senyo SE, Steinhauser ML, Pizzimenti CL, Yang VK, Cai L, Wang M, Wu TD, Guerquin-Kern JL, Lechene CP, Lee RT. Mammalian heart renewal by pre-existing cardiomyocytes. Nature. 2013; 493: 433-436. https://doi. org/10.1038/nature11682.

2. Senyo SE, Lee RT, Kühn B. Cardiac regeneration based on mechanisms of cardiomyocyte proliferation and differentiation. Stem Cell Res. 2014; 13: 532-541. https:// doi.org/10.1016/j.scr.2014.09.003.

3. Kajstura J, Rota M, Whang B, Cascapera S, Hosoda T, Bearzi C, Nurzynska D, Kasahara H, Zias E, Bonafé M, Nadal-Ginard B, Torella D, Nascimbene A, et al. Bone marrow cells differentiate in cardiac cell lineages after infarction independently of cell fusion. Circ Res. 2005; 96 : 127-137.

4. Song YH, Pinkernell K, Alt E. Stem cell induced cardiac regeneration: fusion/mitochondrial exchange and/or transdifferentiation? Cell Cycle. 2011; 10: 2281-2286. https://doi.org/10.4161/cc.10.14.16513

5. Leri A, Rota M, Pasqualini FS, Goichberg P. Anversa P Origin of cardiomyocytes in the adult heart. Circ Res. 2015; 116: $150-166$.

6. Nadal-Ginard B, Ellison GM, Torella D. The cardiac stem cell compartment is indispensable for myocardial cell homeostasis, repair and regeneration in the adult. Stem Cell Res. 2014; 13: 615-630. https://doi.org/10.1016/j. scr.2014.04.008.

7. Omatsu-Kanbe M, Matsuura H. A novel type of selfbeating cardiomyocytes in adult mouse ventricles. Biochem Biophys Res Commun. 2009; 381: 361-366. http://dx.doi. org/10.1016/j.bbrc.2009.02.048.

8. Kimura W, Xiao F, Canseco DC, Muralidhar S, Thet S, Zhang HM, Abderrahman Y, Chen R, Garcia JA, Shelton JM, Richardson JA, Ashour AM, Asaithamby A, et al. Hypoxia fate mapping identifies cycling cardiomyocytes 
in the adult heart. Nature. 2015; 523: 226-230. https://doi. org/10.1038/nature14582.

9. Tang XL, Li Q, Rokosh G, Sanganalmath SK, Chen N, Ou Q, Stowers H, Hunt G, Bolli R. Long-Term Outcome of administration of c-kitPOS cardiac progenitor cells after acute myocardial infarction: transplanted cells do not become cardiomyocytes, but structural and functional improvement and proliferation of endogenous cells persist for at least one year. Circ Res. 2016; 118: 1091-1105.

10. Sharma A, Wu SM. Members Only: Hypoxia-Induced CellCycle Activation in Cardiomyocytes. Cell Metab. 2015; 22: 365-3666. https://doi.org/10.1016/j.cmet.2015.08.004.

11. Broughton KM, Wang BJ, Firouzi F, Khalafalla F, Dimmeler S, Fernandez-Aviles F, Sussman MA. Mechanisms of Cardiac Repair and Regeneration. Circ Res. 2018; 122: 1151-1163

12. Tompkins BA, Balkan W, Winkler J, Gyöngyösi M, Goliasch G, Fernández-Avilés F, Hare JM. Preclinical Studies of Stem Cell Therapy for Heart Disease. Circ Res. 2018; 122:1006-1020.

13. Belostotskaya GB, Golovanova TA. Characterization of contracting cardiomyocyte colonies in the primary culture of neonatal rat myocardial cells: A model of in vitro cardiomyogenesis. Cell Cycle. 2014; 13: 910-918. https:// doi.org/10.4161/cc.27768.

14. Belostotskaya G, Nevorotin A, Galagudza M. Identification of cardiac stem cells within mature cardiac myocytes. Cell Cycle. 2015; 14: 3155-3162. https://doi.org/10.1080/15384 101.2015.1078037.

15. Roubinet C, Cabernard C. Control of asymmetric cell division. Curr Opin Cell Biol. 2014; 31: 84-91. https://doi. org/10.1016/j.ceb.2014.09.005.

16. Urbanek K, Cesselli D, Rota M, Nascimbene A, De Angelis A, Hosoda T, Bearzi C, Boni A, Bolli R, Kajstura J, Anversa P, Leri A. Stem cell niches in the adult mouse heart. Proc Natl Acad Sci U S A. 2006; 103: 9226-31. https://doi. org/10.1073/pnas.0600635103.

17. Rando TA. Stem cells, ageing and the quest for immortality. Nature. 2006; 441: 1080-1086. https://doi.org/10.1038/ nature04958.

18. Beltrami AP, Cesselli D, Beltrami CA. At the stem of youth and health. Pharmacol Ther. 2011; 129: 3-20. https://doi. org/10.1016/j.pharmthera.2010.10.005.

19. Beltrami AP, Barlucchi L, Torella D, Baker M, Limana F, Chimenti S, Kasahara H, Rota M, Musso E, Urbanek K, Leri A, Kajstura J, Nadal-Ginard B, Anversa P. Adult cardiac stem cells are multipotent and support myocardial regeneration. Cell. 2003; 114: 763-776. http://dx.doi. org/10.1016/S0092-8674(03)00687-1.

20. Bearzi C, Rota M, Hosoda T, Tillmanns J, Nascimbene A, De Angelis A, Yasuzawa-Amano S, Trofimova I, Siggins RW, Lecapitaine N, Cascapera S, Beltrami AP, D'Alessandro DA, et al. Human cardiac stem cells. Proc Natl Acad Sci U S A. 2007; 104: 14068-14073. https://doi. org/10.1073/pnas.0706760104.
21. Hosoda T, D'Amario D, Cabral-Da-Silva MC, Zheng $\mathrm{H}$, Padin-Iruegas ME, Ogorek B, Ferreira-Martins J, Yasuzawa-Amano S, Amano K, Ide-Iwata N, Cheng W, Rota M, Urbanek K, et al. Clonality of mouse and human cardiomyogenesis in vivo. Proc Natl Acad Sci U S A. 2009; 106: 17169-17174. https://doi.org/10.1073/ pnas.0903089106.

22. Anversa P, Kajstura J, Rota M, Leri A. Regenerating new heart with stem cells. J Clin Invest. 2013; 123: 62-70. https://doi.org/10.1172/JCI63068.

23. Oh H, Bradfute SB, Gallardo TD, Nakamura T, Gaussin V, Mishina Y, Pocius J, Michael LH, Behringer RR, Garry DJ, Entman ML, Schneider MD. Cardiac progenitor cells from adult myocardium: homing, differentiation, and fusion after infarction. Proc Natl Acad Sci U S A. 2003; 100: 12313 12318. https://doi.org/10.1073/pnas.2132126100.

24. Matsuura K, Nagai T, Nishigaki N, Oyama T, Nishi J, Wada H, Sano M, Toko H, Akazawa H, Sato T, Nakaya H, Kasanuki H, Komuro I. Adult cardiac Sca-1-positive cells differentiate into beating cardiomycytes. J Biol Chem. 2004; 279: 11384 -11391. https://doi.org/10.1074/jbc. M310822200.

25. Wang X, Hu Q, Nakamura Y, Lee J, Zhang G, From $\mathrm{AH}$, Zhang J. The role of the Sca-1+/CD31- cardiac progenitor cell population in postinfarction left ventricular remodeling. 2006; 24: 1779-1788. https://doi.org/10.1634/ stemcells.2005-0386.

26. van Vliet P, Roccio M, Smits AM, van Oorschot AA, Metz $\mathrm{CH}$, van Veen TA, Sluijter JP, Doevendans PA, Goumans MJ. Progenitor cells isolated from the human heart: a potential cell source for regenerative therapy. Neth Heart J. 2008; 16: 163-169.

27. Laugwitz KL, Moretti A, Lam J, Gruber P, Chen Y, Woodard S, Lin LZ, Cai CL, Lu MM, Reth M, Platoshyn O, Yuan JX, Evans S, Chien KR. Postnatal is11+ cardioblasts enter fully differentiated cardiomyocyte lineages. Nature. 2005; 433:647-653. https://doi.org/10.1038/nature03215.

28. Genead R, Danielsson C, Andersson AB, Corbascio M, Franco-Cereceda A, Sylvén C, Grinnemo KH. Islet-1 cells are cardiac progenitors present during the entire lifespan: from the embryonic stage to adulthood. Stem Cells Dev. 2010; 19: 1601-1615. https://doi.org/10.1089/ scd.2009.0483.

29. Reinecke H, Minami E, Zhu WZ, Laflamme MA. Cardiogenic differentiation and transdifferentiation of progenitor cells. Circ Res. 2008; 103: 1058-1071.

30. Steinhauser ML, Lee RT. Regeneration of the heart. EMBO Mol Med. 2011; 3: 701-12. https://doi.org/10.1002/ emmm.201100175.

31. Gu Y, Yi F, Liu GH, Izpisua Belmonte JC. Beating in a dish: new hopes for cardiomyocyte regeneration. Cell Research. 2013; 23: 314-316. https://doi.org/10.1038/cr.2012.163.

32. Omatsu-Kanbe M, Yamamoto T, Mori Y, Matsuura H. Self-beating atypically shaped cardiomyocytes survive a long-term postnatal development while preserving the 
expression of fetal cardiac genes in mice. J Histochem Cytochem. 2010; 58: 543-551. https://doi.org/10.1369/ jhc.2010.955245.

33. Malliaras K, Ibrahim A, Tseliou E, Liu W, Sun B, Middleton RC, Seinfeld J, Wang L, Sharifi BG, Marbán E. Stimulation of endogenous cardioblasts by exogenous cell therapy after myocardial infarction. EMBO Mol Med. 2014; 6: 760-777. https://doi.org/10.1002/emmm.201303626.

34. Malliaras K, Vakrou S, Kapelios CJ, Nanas JN. Innate heart regeneration: endogenous cellular sources and exogenous therapeutic amplification. Expert Opin Biol Ther. 2016; 16: 1341-1352. https://doi.org/10.1080/14712598.2016.1218846.

35. Foglia MJ, Poss KD. Building and re-building the heart by cardiomyocyte proliferation. Development. 2016; 143:729740. https://doi.org/10.1242/dev.132910.
36. Uygur A, Lee RT. Mechanisms of Cardiac Regeneration. Dev Cell. 2016; 36: 362-374. https://doi.org/10.1016/j. devcel.2016.01.018.

37. Graham E, Bergmann O. Dating the Heart: Exploring Cardiomyocyte Renewal in Humans. Physiology (Bethesda). 2017; 32: 33-41. https://doi.org/10.1152/ physiol.00015.2016. 